\title{
A Mature Cystic Teratoma of the Urinary Bladder
}

\author{
Safdar Shah, Wajid Ali, Imran Ansari and Shams-ul-Islam \\ Department of Urology and Renal Transplant, Mayo Hospital, King Edward Medical University, Lahore, Pakistan
}

\begin{abstract}
We report a case of a mature cystic teratoma of urinary bladder in a 17-year female, which is extremely rare. The patient presented with pain in suprapubic region for one year. On computerized tomography (CT) of abdomen and pelvis, a welldefined, enhancing heterogeneous soft tissue density lesion measuring $2.5 \times 2.3 \times 3 \mathrm{~cm}$ with mean density of 48 Hounsfield unit was found originating from the superior wall of the urinary bladder and projecting into the lumen. Cystoscopy showed a $2 X 2 \mathrm{~cm}$ growth containing concretions. Resection of the lesion was done with wide margin by transurethral resection of bladder tumor (TURBT). Histopathological examination showed fragments of skin, sebaceous glands, fat and muscle cells, confirming mature cystic teratoma.
\end{abstract}

Key Words: Urinary bladder, Dermoid cyst, Teratoma.

How to cite this article: Shah S, Ali W, Ansari I and Islam SU. A mature cystic teratoma of the urinary bladder. J Coll Physicians Surg Pak 2019; 29 (Supplement 2):S160-S162.

\section{INTRODUCTION}

Cystic teratomas are germ cell tumors, which are thought to represent developmental anomalies. They contain tissues representative of more than one germ cell layer and are commonly found in the ovaries, but may also be discovered at other locations, especially in the para-axial and midline structures. Teratomas may be asymptomatic or variably symptomatic.

After growing to a large size, they may cause complications, according to the involved organ. Teratomas of bladder may present with clinical manifestations of irritative lower urinary tract symptoms or retention of urine. They are usually found incidentally during clinical examination, in radiological studies, or in non-related abdominal operations. In gross appearance, teratomas have solid and cystic areas. Most of teratomas have normal tumor markers in serum but sometimes they can result in increased $\alpha$-fetoprotein (AFP) levels. Urinary bladder is the rarest site.

The first case of urinary bladder teratoma was reported by Marsden et al. in 1981, who studied the database of 137 children (0-14 years of age) from Manchester University Children's Tumour Registry (MUCTR).

Misra et al. in 1997 described the first case of urinary bladder teratoma in a young Indian girl with a partially mobile mass on per rectal examination. ${ }^{1}$ The mass had tufts of hair on cystoscopic examination; a provisional

Correspondence to: Prof. Safdar Shah, Department of Urology and Renal Transplant, Mayo Hospital, King Edward Medical

University, Lahore, Pakistan

E-mail:drsafdar-ali@hotmail.com

Received: December 26, 2018; Revised: July 01, 2019;

Accepted: July 10, 2019 diagnosis of bladder teratoma was confirmed by histopathological examination and the mass was resected surgically. ${ }^{1}$ To our knowledge, no case of dermoid cyst of urinary bladder has been reported from Pakistan till now.

Herein, we report a case of dermoid cyst of urinary bladder and describe the ultrasound, computed tomography and cystoscopic findings along with histological appearance of the tumor in a young girl.

\section{CASE REPORT}

A 17-year female reported to our hospital with suprapubic pain for one year; and painless, total hematuria twice in a year. There was no previous medical illness or history of any surgical intervention. Physical examination was unremarkable. Laboratory investigations revealed normal hemoglobin level, total leukocyte count (TLC) and renal function tests. Urine analysis was not significant.

Ultrasound of kidney, ureter and bladder (KUB) revealed a well-defined rounded to oval-shaped mass having echogenic wall with solid echogenic component originating from the posterior wall of urinary bladder, measuring $2.4 \times 2 \mathrm{~cm}$ in size. Rest of urinary bladder, kidneys and ureters were normal.

CT scan of abdomen and pelvis was performed and showed well-defined heterogeneous soft tissue density lesion measuring $2.5 \times 2.3 \times 3.3 \mathrm{~cm}$ with mean density of 48 Hounsfield units, originating from the superior wall of bladder and projecting into the lumen (Figure 1). The lesion appeared as a filling defect on full bladder.

Cystoscopy and transurethral wide resection was done and specimen was sent for histopathology examination. Result revealed fragments of skin with sebaceous glands, fat, nerve and muscle cells and was consistent with mature cystic teratoma (Dermoid cyst) (Figure 2). 


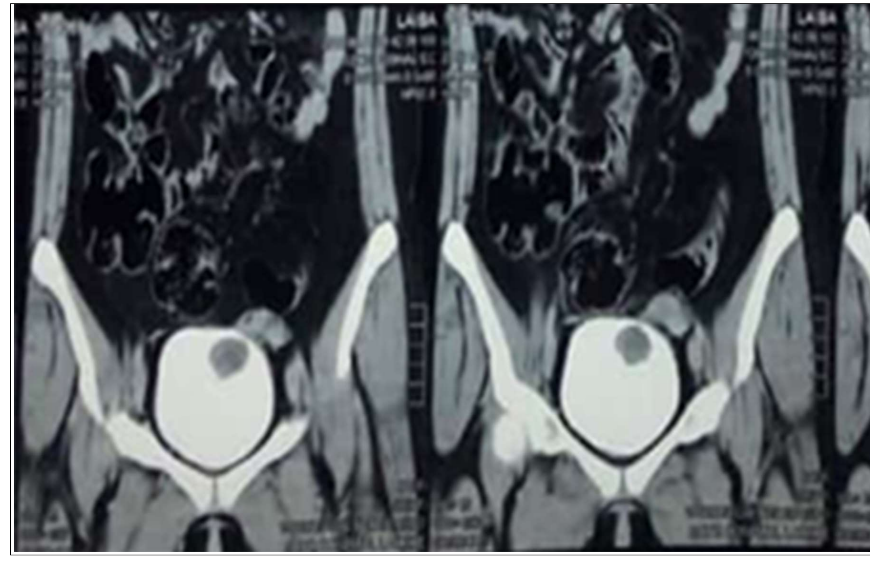

Figure 1: CT-scan showing soft tissue density enhancing lesion in superior wall of bladder and projecting into lumen.

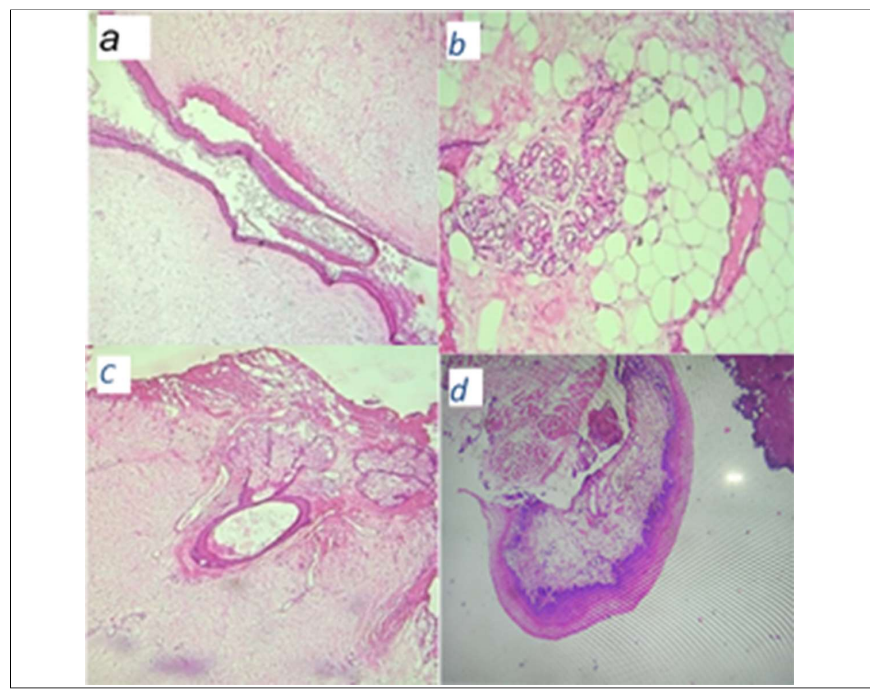

Figure 2: Histopathology of the mass. (a) showing keratin debris and squamous epithelium. (b) showing skin adnexal structures and adipose tissue. (c) showing hair follicle, sebaceous glands and adipose tissue. (d) showing squamous epithelium and skeletal muscle.

We planned for cystectomy but patient and her parents refused. So we put her on follow-up. In our 3-monthly follow-up, cystoscopy was done and till now no growth was reported. The follow-up is going on.

\section{DISCUSSION}

Teratomas of midline origin usually result from abnormal germ cells when neural tube closes at 3 rd to $5^{\text {th }}$ week of gestation.2 Cystic teratoma of urinary bladder is a rare entity, and only few cases are reported in literature. ${ }^{3}$ Cystic teratomas are usually encapsulated; and well differentiated tumors are derived from two or three layers of germinal epithelium. These germinal layers either form hair follicles, sweat glands and pockets of serum or give rise to fat, blood, bone, nail, teeth, cartilage and thyroid tissue. ${ }^{4}$ Dermoid cysts are usually formed by skin sequestration along the lines of embryonic closure that contain mature skin tissue with appendages like, hair follicles and sweat glands. The presence of extraneous tissues such as blood, fat, bone, nails, teeth, eyes, cartilage and thyroid tissue points to its origin from germ cells. Dermoid cysts are usually benign. Some benign cysts are diagnosed on the passage of hair in urine. ${ }^{5}$ About $20 \%$ of ovarian neoplasms are dermoid cysts, which are the commonest germ cell tumor of the ovary. 6 It may occur at multiple sites in the body, but urinary bladder is one of the rarest sites. It is frequently diagnosed on ultrasonography (USG) as an echogenic mass which shows a posterior acoustic shadow. Mais et al. reported a sensitivity of $58 \%$ and specificity of $99 \%$ in diagnosing a mature cystic teratoma by abdominal USG.7

CT scan is a highly sensitive tool in demonstrating fat and calcification. A Rokitansky nodule might be seen as a focal mural thickening or a rounded structure protruding into the cystic lumen. Regarding treatment, the primary approach is total removal of the tumor by cystectomy, either open or by laparoscopic technique. Studies suggest that laparoscopic cystectomy appears to be a safe, feasible and minimally invasive alternative to radical cystectomy with perioperative safety, pathologic and oncologic efficacy and comparable in postoperative neobladder function and fewer complications. The other alternatives are radiotherapy and chemotherapy for the tumors that show malignant charac-teristics. ${ }^{8}$

Transurethral resection of the mass was adopted in our case which is also reported choice of treatment. ${ }^{9}$ However, cystectomy is the definite management of this tumor. ${ }^{10}$

This case is important in terms of differential diagnosis of bladder mass with unknown origin. Bladder dermoid should be kept in mind in case of unusual bladder mass and the patient can be reassured that it is benign.

\section{PATIENT'S CONSENT:}

Formal and informal consents were taken from the patient while she was admitted in the Ward, which is part of official document of the Hospital.

\section{CONFLICT OF INTEREST:}

Authors declared no conflict of interest.

\section{AUTHORS' CONTRIBUTION:}

SS, IA, WA, SUI: Contributed in compiling and processing of final drafting of the manuscript.

\section{REFERENCES}

1. Jain C, Mittal MK, Shiraz F. An extremely rare case of dermoid cyst of urinary bladder. Indian J Radiol Imaging 2017; 27:302-5.

2. Okeke LI, Ogun GO, Etukakpan BR, lyama A, Adeoye AO, Duduyemi BM. Dermoid cyst of the urinary bladder as a differential diagnosis of bladder calculus. J Med Case Rep 2007; 1:32.

3. Reddy P. Diagnostic histopathology of tumours. Med J Armed Forces India 1996; 52:209.

4. Crum CP. Female genital tract - ovarian tumors. In: Kumar V, 
Abass AK, Fausto N, editor. Robbins pathologic basis of disease. 7. Philadelphia: Saunders, Elsevier; 2004. pp.1099-104.

5. Jain SK, Kaza RC, Vindal A, Bains L. Vesical dermoid: An unusual presentation. Int J Urol 2010; 17:824-5.

6. Rha SE, Byun JY, Jung SE, Kim HL, Oh SN, Kim H, et al. Atypical CT and MRI manifestations of mature ovarian cystic teratomas. AJR Am J Roentgenol 2004; 183:743-50.

7. Mais V, Guerriero S, Ajossa S, Angiolucci M, Paoletti AM, Melis GB. Transvaginal ultrasonography in the diagnosis of cystic teratoma. Obstet Gynecol 1995; 85:48-52.
8. Tang K, Li H, Xia D, Hu Z, Zhuang Q, Liu J, et al. Laparoscopic versus open radical cystectomy in bladder cancer: A systematic review and meta-analysis of comparative studies. PLoS One 2014; 9:e95667.

9. Prihadi JC, Kusumajaya C. Mature teratoma of the bladder in adolescence: A case report and literature review. Res Rep Urol 2018; 10:39-42.

10. Vera, Safriadi F. Mature (benign) cystic retrovesical teratoma in a 49-year-old male: A case report and literature review. J Med Case Rep 2016; 4:153-7.

.......... 